\title{
Radiology Reporting System Data Exchange With the Electronic Health Record System: A Case Study in Iran
}

\author{
Maryam Ahmadi ${ }^{1}$, Marjan Ghazisaeidi ${ }^{2} \&$ Azadeh Bashiri $^{2}$ \\ ${ }^{1}$ Health Information Management Department, School of Health Management and information Sciences, Iran \\ University of Medical Sciences, Tehran, Iran \\ ${ }^{2}$ Health Information Management Department, School of Allied-Medical Sciences, Tehran University of \\ Medical Sciences, Tehran, Iran \\ Correspondence: Azadeh Bashiri, Health Information Management, School of Allied-Medical sciences, Tehran \\ University of Medical Sciences, Tehran, Iran. Tel: 98-917-501-4231. E-mail: a-bashiri@razi.tums.ac.ir
}

Received: November 12, 2014 Accepted: January 14, 2015 Online Published: March 16, 2015

doi:10.5539/gjhs.v7n5p208ＵRL: http://dx.doi.org/10.5539/gjhs.v7n5p208

\begin{abstract}
Introduction: In order to better designing of electronic health record system in Iran, integration of health information systems based on a common language must be done to interpret and exchange this information with this system is required.

Background: This study provides a conceptual model of radiology reporting system using unified modeling language. The proposed model can solve the problem of integration this information system with the electronic health record system. By using this model and design its service based, easily connect to electronic health record in Iran and facilitate transfer radiology report data.
\end{abstract}

Methods: This is a cross-sectional study that was conducted in 2013. The study population was 22 experts that working at the Imaging Center in Imam Khomeini Hospital in Tehran and the sample was accorded with the community. Research tool was a questionnaire that prepared by the researcher to determine the information requirements. Content validity and test-retest method was used to measure validity and reliability of questioner respectively. Data analyzed with average index, using SPSS. Also Visual Paradigm software was used to design a conceptual model.

Result: Based on the requirements assessment of experts and related texts, administrative, demographic and clinical data and radiological examination results and if the anesthesia procedure performed, anesthesia data suggested as minimum data set for radiology report and based it class diagram designed. Also by identifying radiology reporting system process, use case was drawn.

Conclusion: According to the application of radiology reports in electronic health record system for diagnosing and managing of clinical problem of the patient, with providing the conceptual Model for radiology reporting system; in order to systematically design it, the problem of data sharing between these systems and electronic health records system would eliminate.

Keywords: structured radiology report, information needs, minimum data set, the electronic health record system in Iran

\section{Introduction}

Electronic Health Record is the most important tool for delivering high quality care through the sharing of health information. International research shows that the benefits of (E-Health) electronic health record increases when it is accessible and can be used by all those involved in patient care (Sadiughi, Delgoshaei, Foozonkhah, Tofighi, \& Khalesi, 2006).

This record is a source of patient data that are either directly imported or transferred from external applications (Nguyen, Bellucci, \& Nguyen, 2014). So it is clear that the formation of this file is very slow and time consuming to provide data that will be generated from various resources over time. The Iran EHR system represents a set of applications that run in the proper context and the feasibility of electronic health records makes it possible. In other words, the lack of an integrated health information and possibly in different parts, has 
led to the emergence of this system (Seidy \& Vaseghi, 2011; Sistrom, Lanier, \& Mancuso, 2004).

Hence, due to the decentralization of information, the better designed EHR system requires standardized and significant data exchange with the system (Seidy \& Vaseghi, 2011; unknown author, 2011).

Defining The Minimum Data Set is an important step in creating a national registration system that gives the ability to identify patients to medical institutions and meet governmental requirement, Own internal needs and medical society(Moghaddasi, 2005; Karimi, Isfahani, Farzandipour, \& Esmaeili , 2011).

Radiology information system is a part of the EHR Software that designed to film storing, Interpreting and presenting radiology reports, recording and retrieval of patient data and Radiology Photography and includes the following systems: patient tracking, image tracking, examination, radiology reporting, and management system. Radiology reporting subsystem designed for registering radiology findings in the computerized clinical database (Chew \& Felix, 1999; Clayton, Ostler, Gennaro, Beatty, \& Frerick, 1980; Dunnick \& Langlotz, 2008).

In general, the reporting assumed as a process for findings and diagnosis information extracting from images exported from any kind of modalities. According to the Radiological Society of North America these reports should include the basic defined elements, such as patient identifier, interventions description, and clinical description and photography findings. In 1922, Hickey made a request to standardize radiology reports. Now days, after more than 80 years since, there is still the problem of variability and quality of radiology reports. According to the royal college of radiologists in London Standardization of structure, content and setting time of this report, will increase the clinical, educational, research, quality improvement, accreditation and financial functionality of them. One way to achieve this goal is the use of structured reporting systems rather than conventional reporting free texts (Sistron, Lanier, \& Mancuso, 2004; Noumeir Rita, 2006; Johnson, Chen, Zapadka, Lyders, \& Littenberg, 2010).The term structured reporting represents a set of computer tools that aim at reducing variability and increasing clinical use of radiologist interpretations (Dunnick \& Langlotz, 2008).

Radiology Data recording is an important means to convey the results of radiologic findings by doctors and Helps them better understand the content of the reports and so has a great impact on how care is (Brenner, 2009; Kahn, Langlotz, Burnside, Carrino, Channin, Hovsepian, \& Rubin, 2009). On the other hand, given that these reports are considered as an important part of the patient's medical record, Application of Modeling Techniques and Tools that show Radiology Reporting System Data Exchange with EHR in the graphical form, is important. Data modeling is documenting processes and events that are done during the development and design of software applications. Data modeling tools, Simplify the design of complex systems into Understandable and simple view of data flow and processes (Chew \& Felix, 1999).

In the past, different software engineering techniques and tools for the analysis of health care systems were used. Recently, the concept of object-oriented analysis and design using Unified Modelling Language systems, emerged as new tools for modeling healthcare systems (Clayton, Ostler, Gennaro, Beatty, \& Frederick, 1980).

Unified modeling language, is an object-oriented modeling language that used to describe the concepts of objectoriented systems (Dunnick \& Langlotz, 2008). It typically includes a number of visual diagrams to describe the structural and behavioral features of the software (Brenner, 2009). The advantages of this language, are standard communication and Stable method for documentation (Dunnick \& Langlotz, 2008). Since For widespread adoption of electronic health records, it is essential that with accurate design and software analysis, the standardization process is coordinated with the implementation, thus object-oriented design and analysis is a good tool for modeling complex software systems as well EHR system is (Brenner, 2009). The purpose of establishing an electronic health records system in Iran is the integration of local information systems, Due to the distribution of these softwares, analysis and exchange of information is not possible (Seidy \& Vaseghi, 2011). Utilizes the Unified Modeling Language, that in fact is the standard for modeling information and processes, Systematic design of radiology reporting system can be done and by developing a conceptual model based on the Unified Modeling Language, The problem of information exchange between this system and electronic health records system be removed. In This study we assessed the information needs of users and by determining the MDS, Use case diagram for a better understanding of the operational requirements of the system were plotted.

\section{Methods}

This study was an applied and a descriptive cross - sectional study that in the first half of 2013 has been carried out. The study population includes users of Radiology reporting systems in the one of general hospitals, imaging center, consisting of 13 radiologists, three anesthesiologists, three Insurance Expert and three GP. Due to the small number of users, the sampling was not done. A questionnaire was used to collect data that made by the study of literature on the radiology report content and format standards and related articles on the laboratory, 
mortality, the flu and myocardial infarction data exchange with EHR system (unknown author, 2011; Shahmoradi, Torabi, \& Safdari, 2012).

The questionnaire included a list of required data in the radiology reporting system in the eleven parts include: Management information, demographics, insurance, imaging procedures, anesthesia, history of previous actions, radiologist observations, radiologists interpreting, annex information signs and approval of responsible persons. For questionary validation, the content validity method was used. To assess reliability, test-retest method was used. In this way, from the same group out of study population, eight were selected and they were asked to complete the questionnaire. This work was performed twice with an interval of ten days. The correlation coefficient was determined to be $86 \%$ and the reliability of the questionnaire was confirmed. Questionnaires were used for completion by study population and they were asked to make choices based on their degree of importance from one to ten to rate So that the greatest score was 10 and a score of 1 was assigned to the least important. Finally, analysis of the data by using descriptive statistics were performed by SPSS application. According to experts, the collection of data elements for the radiology reporting system was determined and rated. The mean values were calculated for each data element and its associated descriptive tables were drawn. The following were identified as priorities:

priority $1=$ average $9-10$

Priority $2=$ average $8-8.99$

Priority $3=$ average $7-7.99$

Priority 4 = average 6-6.99

Priority $5=$ average 5-5.99

Priority 6 =average $4-4.99$

To determine the minimum amount of data, data elements were selected with at least 5 and According to the relevant articles in the field of radiology minimum data reporting system and similar researches in the field of information exchange with electronic health records system, the MDS of these reports were provided. Also the use case diagrams were drawn up via Visual paradigm which is a non-commercial and open source software and is based on UML 2.0 .

\section{Results}

$67 \%$ of insurance experts, $33 \%$ of general practitioners, $67 \%$ of anesthetists and $54 \%$ of radiologists in the research population were men And the rest were women. Overall, more women than men were in the study population. The largest age group (55\%) belonged to the age group below 40 years and most participants had experience of less than 10 years (about 55\%). Table 1 shows the minimum data set for the radiology reporting system to exchange with the electronic health records.

Based on the data analysis method described in the research method, Data elements with more than 5 priorities in the model were included in the model. Use case diagram reporting system for information exchange with electronic health records system describes that What is the reporting system should be done and by whom. In this diagram, radiologists, surgeons, anesthesiologists and Compliance Officer, as the main actor and an expert in insurance, patient insurance system, coding systems and electronic health records systems as another actor of the model was determined. Operations that were considered in this diagram include: Register, signing-in, editing reports, confirming the report, adding new information to report, deleting report, searching reports, viewing reports, share reports with external systems, reminders, digital signatures, clinical data recording, Anesthesia data recording, Reception and logout. 
Table 1.

\begin{tabular}{|c|c|c|c|c|}
\hline \multicolumn{2}{|r|}{ Data element } & \multicolumn{3}{|c|}{ Data element } \\
\hline & Number of encounter & \multirow{22}{*}{$\begin{array}{l}\text { Administrative } \\
\text { data set }\end{array}$} & Name & \multirow{3}{*}{$\begin{array}{l}\text { Imaging } \\
\text { facility }\end{array}$} \\
\hline & date of service & & identifier & \\
\hline & \multirow{2}{*}{ time of service } & & address & \\
\hline & & & first and last name & \multirow{5}{*}{$\begin{array}{l}\text { referring } \\
\text { physician }\end{array}$} \\
\hline & Place of stay & & identifier & \\
\hline & Informed consent & & specialty & \\
\hline \multirow[t]{16}{*}{$\begin{array}{l}\text { Demographic } \\
\text { data set }\end{array}$} & first and last name & & $\begin{array}{l}\text { address and phone } \\
\text { number }\end{array}$ & \\
\hline & father name & & $\begin{array}{l}\text { time, date and digital } \\
\text { sign }\end{array}$ & \\
\hline & medical record number & & first and last name & \multirow{3}{*}{$\begin{array}{l}\text { admitting } \\
\text { physician }\end{array}$} \\
\hline & birth date & & identifier & \\
\hline & birth place & & $\begin{array}{l}\text { time, date and digital } \\
\text { sign }\end{array}$ & \\
\hline & educational level & & first and last name & \multirow{3}{*}{ radiologist } \\
\hline & gender & & identifier & \\
\hline & age & & $\begin{array}{l}\text { time, date and digital } \\
\text { sign }\end{array}$ & \\
\hline & \multirow{3}{*}{ weight } & & first and last name & \multirow{3}{*}{ anesthesiologis } \\
\hline & & & identifier & \\
\hline & & & $\begin{array}{l}\text { time, date and digital } \\
\text { sign }\end{array}$ & \\
\hline & identification number & & \multicolumn{2}{|l|}{ admission date } \\
\hline & national code & & \multicolumn{2}{|l|}{ admission time } \\
\hline & $\begin{array}{l}\text { geographic information(the country, } \\
\text { province, city, town, village) }\end{array}$ & & \multicolumn{2}{|c|}{$\begin{array}{l}\text { admission type(inpatient/ ambulatory/ } \\
\text { emergency) }\end{array}$} \\
\hline & postal code & & \multicolumn{2}{|l|}{ admission Ward } \\
\hline & patient address & & \multicolumn{2}{|l|}{ reason for encounter } \\
\hline
\end{tabular}

\begin{tabular}{|c|c|c|}
\hline \multicolumn{3}{|c|}{ Data element } \\
\hline \multirow{11}{*}{$\begin{array}{l}\text { Radiology } \\
\text { data set }\end{array}$} & \multicolumn{2}{|c|}{ Encoded findings } \\
\hline & \multicolumn{2}{|c|}{ Image annotations } \\
\hline & $\begin{array}{l}\text { nature of } \\
\text { complication }\end{array}$ & \multirow[t]{2}{*}{$\begin{array}{l}\text { Complications (including } \\
\text { contrast reactions) }\end{array}$} \\
\hline & treatment & \\
\hline & \multicolumn{2}{|c|}{ Recommendation } \\
\hline & \multicolumn{2}{|l|}{ Assessment } \\
\hline & \multicolumn{2}{|l|}{ Plan } \\
\hline & \multicolumn{2}{|c|}{ radiologist's diagnosis } \\
\hline & \multicolumn{2}{|c|}{ Date of previous exams reviewed } \\
\hline & \multicolumn{2}{|c|}{ type of previous exams reviewed } \\
\hline & \multicolumn{2}{|c|}{ Pertinent observations from prior } \\
\hline
\end{tabular}

\begin{tabular}{|l|l|}
\hline \multicolumn{2}{|c|}{ Data element } \\
\hline \multirow{4}{*}{ Insurance data set } & $\begin{array}{l}\text { Serial number of the patient's } \\
\text { insurance }\end{array}$ \\
\cline { 2 - 2 } & Expiration of patient insurance \\
\cline { 2 - 3 } & insurance type \\
\cline { 2 - 2 } & insured number \\
\cline { 2 - 3 } & insurance Box \\
\cline { 2 - 2 } & Insurer Name \\
\cline { 2 - 2 } & Insurer ID \\
\cline { 2 - 2 } & insured name \\
\hline Clinical data set & primary diagnosis \\
\cline { 2 - 2 } & ICD-10 according to primary \\
\hline
\end{tabular}




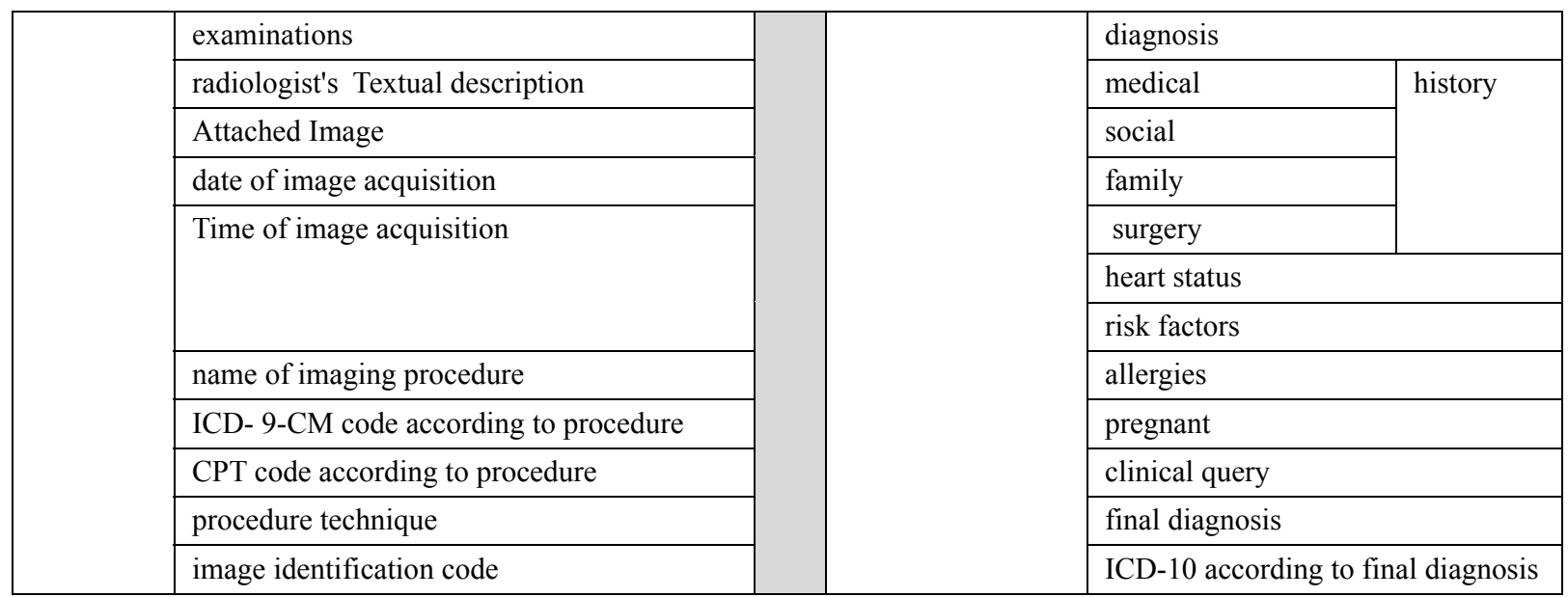

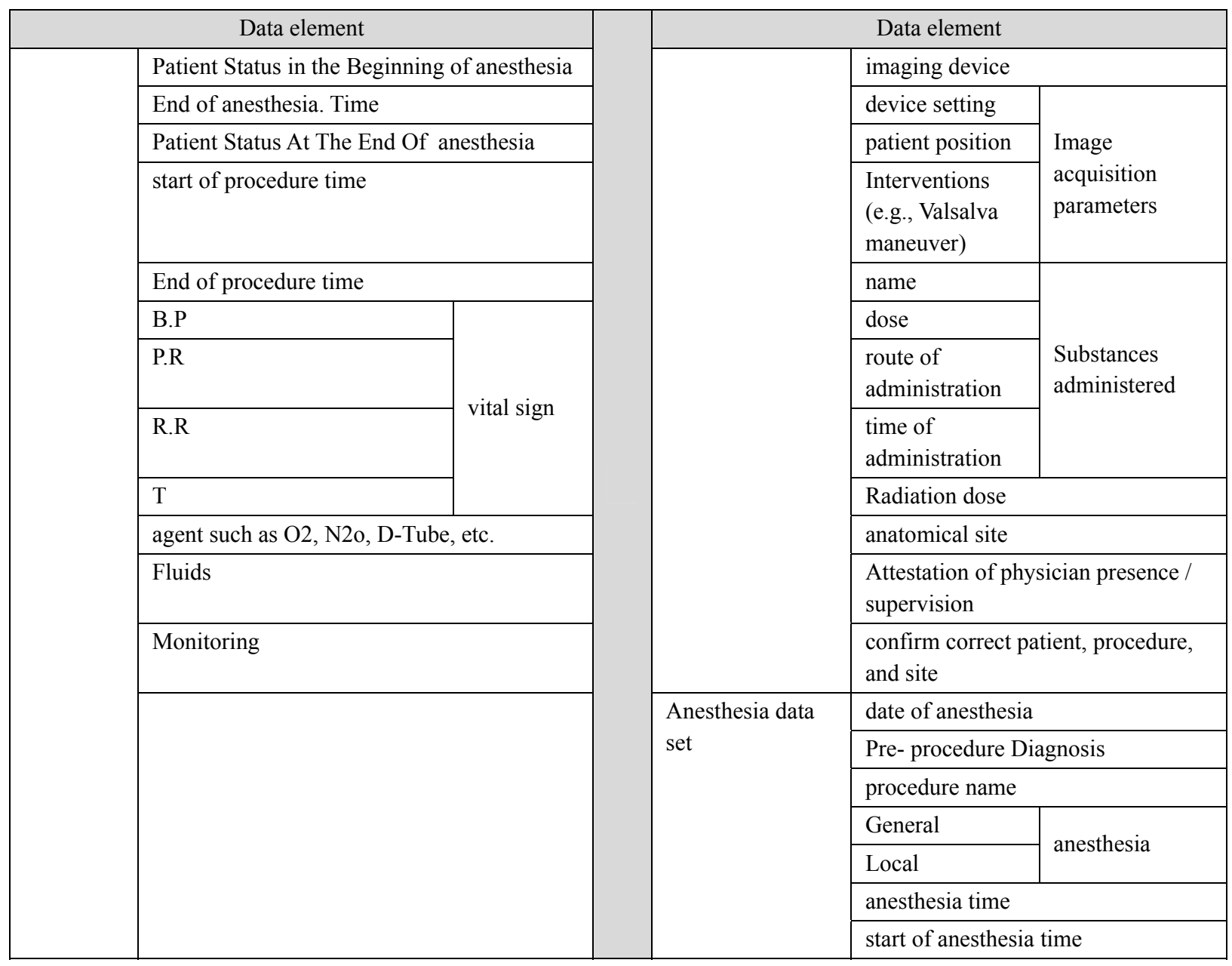

\section{Discussion}

Designing an information system is vital for organizations because each organization has a comprehensive, timely, and correct data that access to these data in the shortest possible time, provides the organization's great success. Since one of the important functions of clinical information systems is to meet the information needs of professionals, in designing these systems and presenting the model of them, the assessment of end-users is necessary. This information needs should be considered to establish a standard data collection system (Boonn \& Langlotz, 2009). Based on these findings, the reporting system minimum data set for the exchange with the electronic health record system were included: management, identity, insurance, clinical and imaging 
examination data and If the patient is put under anesthesia, System designers should also consider the anesthesia in the minimum data set. Information Standards Board (ISB), in response to the lack of accurate data for diagnostic imaging examinations, for patients in the National Health Service in England, has introduced Minimum Data Set for diagnostic imaging in the three parts: demographic, references and imaging data (unknown, 2013).

Radiology Schools.com, that is a comprehensive website to provide quality services to students and academic community, cited the main body of radiology reports in five parts: information about materials and methods, findings, clinical problems, differential diagnosis, potential limitations and comparative information. Radiology Society of North America, Australia and New Zealand are also have mentioned these elements in different terms (Plumb, Grieve, \& Khan, 2009; Shahmoradi, Torabi, \& Safdari, 2012; unknown author, 2011). Results showed that radiologists need clinical information when they are interpreting radiology images, because this information has an effect on how they interpreting and Contribute to patient care management and facilitate an accurate diagnosis by a physician (unknown, 2013). In all studies, importance of existing clinical information and medical history of patient was cited. Also, given that one of EHR stakeholders are insurance companies that profit from the results of the implementation of an electronic health records system by reducing costs due to reducing duplicate or unnecessary diagnostic interventions, preventing abuses caused by current insurance systems and analysis of financial data alongside clinical data. Therefore, to achieve this, insurance information must be included in the structured radiology reports (Board of the Faculty of Clinical Radiology, 2006). In general, according to studies conducted in other countries and the results of this study, most of introduced MDS are divided into two groups: clinical and nonclinical data.

Management, identification and insurance information are included in the non-clinical data and clinical information, radiology and anesthesia information are included in the clinical data. It should be noted that establish minimum data for radiology reporting systems is necessary for the exchange with the electronic health record systems because these reports are an important part of the medical record and are helpful in the diagnosis and management of future clinical problems and are a good source for research (Plumb et al., 2009; Board of the Faculty of Clinical Radiology, 2006). In the modeling stage, collaboration and comments of all users of this system in defining minimum data set, are necessary.

\section{Conclusions}

In this research, by providing use cases and standard minimum data sets, a model of radiology reporting system for the exchange with the electronic health record systems in Iran based on the user's requirements was proposed. Since during the development and design of software applications, documentation of processes and events required for modelling data, So in order to design a better reporting system for the exchange with electronic health records system, scenario tables and accurate determination of system processes that created during a radiology report and also processes for the exchange of this report with other external systems, are necessary. Also, in this study with identifying the key data elements for reporting system, class diagram was drawn and by specifying processes in the system scenarios, use case diagram was drawn, Then the obtained use case diagram was used to draw other diagrams such as: Activity diagram, sequence diagram, collaboration diagram, state diagram. Hence it is suggested that to develop a reporting system for radiology, firstly the users' needs should be identified and analyzed and then modelled as use case diagrams. Then, based on use case diagrams, the design team starts their work and by drawing other diagrams of reporting system provide an integrated picture of radiology reporting system so that the health system developers with understanding customer needs can create a high quality system.

\section{References}

Board of The Faculty of Clinical Radiology. (2006). Standards for the reporting and interpretation of imaging investigation London. London: The Royal College of Radiologist

Boonn, W. W., \& Langlotz, C. P. (2009). Radiologist Use of and Perceived Need for Patient Data Access. Journal of Digital Imaging, 22, 357-362. http://dx.doi.org/10.1007/s10278-008-9115-2

Brenner, R. J. (2009). On the Logistics of Interpretive Radiology Reporting: Moving Beyond Procrustes. Journal of the American College of Radiology, 6, 544-546. http://dx.doi.org/10.1016/j.jacr.2009.03.005

Chew, \& Felix, S. (1999). Evaluation of clinical experience in a radiology residency program with quantitative profiling: Rationale, methods, and application. Academic Radiology, 6, 102-111.

Clayton, P. D., Ostler, D. B., Gennaro, J. L., Beatty, S. S., \& Fredrick, P. R. (1980). A radiology reporting system based on most likely diagnoses. Computers and Biomedical Research, 13, 258-270. 
Dunnick, N. R., \& Langlotz, C. P. (2008). The Radiology Report of the Future: A Summary of the 2007 Intersociety Conference. Journal of the American College of Radiology, 5, 626-629.

Johnson, A. J, Chen, M. Y., Zapadka, M. E., Lyders, E. M., \& Littenber, G. B. (2010). Radiology Report Clarity: A Cohort Study of Structured Reporting Compared With Conventional Dictation. Journal of the American College of Radiology, 7, 501-506.

Kahn, C. E., Langlotz, C. P., Burnside, E. S., Carrino, J. A., Channin, D. S., Hovsepian, D. M., \& Rubin, D. L. (2009). Toward best practices in radiology reporting. Radiology, 52, 852-6.

Karimi, S., Isfahani, S., Farzandipour, M., \& Esmaeili, M. (2011). Comparative Study of Minimum Data Sets of Health Information Management of Organ Transplantation in Selected Countries and Presenting Appropriate Solution for Iran. Health Information Management, 1, 497-505.

Moghaddasi, H. (Ed.) (2005). Information Quality in Health Care. Tehran: Vajepardaz.

Nguyen, L., Bellucci, E., \& Nguyen, L. T. (2014). Electronic health records implementation: An evaluation of information system impact and contingency factors. International Journal of Medical Informatics, 83, 779796.

Noumeir, R. (2006). Radiology interpretation process modeling. Journal of Biomedical Informatics, 39, 103-114. http://dx.doi.org/10.1016/j.jbi.2005.07.001

Plumb, A. A., Grieve, F. M., \& Khan, S. H. (2009). Survey of hospital clinicians' preferences regarding the format of radiology reports. Clinical Radiology, 64, 386-394. http://dx.doi.org/10.1016/j.crad.2008.11.009

Sadoughi, F., Delgoshaei, B., Foozonkhah, Sh., Tofighi, Sh., \& Khalesi, N. (2006). Designing an Object-oriented Model for Some Key Messages to Support the Electronic Health Record. Journal of Health Administration, 9, 21-30.

Seidy, M., \& Vaseghi, H. (2011a). Guideline for exchange information with Iranian electronic health record system and death registration system. Tehran: Statistic and Information Technology Office of Ministry of Health and Medical Education.

Seidy, M., \& Vaseghi, H. (2011b). Guideline for exchange laboratory tests results with an electronic health record system in Iran. Tehran: Statistic and Information Technology Office of Ministry of Health and Medical Education.

Shahmoradi, L., Torabi, M., \& Safdari, R. (Eds.) (2012). Management of health information technology. Tehran: jafary.

Sistrom, Ch., Lanier, L., \& Mancuso, A. (2004). Reporting instruction for radiology residents1. Academic Radiology, 11, 76-84. http://dx.doi.org/10.1016/S1076-6332(03)00598-1

Unknown Author. (2013). Diagnostic Imaging Dataset. England: Health \& Social Information center.

Unknown Author. (2011a). Radiology Written Report Guideline- Short Version. Sydney: The Royal Australian and New Zealand College of Radiologists.

Unknown Author. (2011b). Sepas introduction [Online]. Tehran: Ministry of Health and Medical Education, Statistics and Information Technology office. Retrieved May 5, 2014, from http://it.behdasht.gov.ir/index.aspx?siteid=101\&siteid=101\&pageid=20351

\section{Copyrights}

Copyright for this article is retained by the author(s), with first publication rights granted to the journal.

This is an open-access article distributed under the terms and conditions of the Creative Commons Attribution license (http://creativecommons.org/licenses/by/3.0/). 